\title{
The future of psychiatry in low- and middle-income countries
}

\author{
V. Patel* \\ London School of Hygiene and Tropical Medicine, London, UK
}

The great shortage, and inequitable distribution, of psychiatrists in low- and middle-income countries is one of the key reasons for the large treatment gap for people with mental disorders. Psychiatrists need to play a public mental health leadership role in increasing the coverage of mental health care through task shifting of effective interventions to non-specialist health workers. Psychiatrists' new roles should include designing and managing such programmes, building clinical capacity, supervision and quality assurance, providing referral pathways and research.

Received 19 November 2008; Revised 29 December 2008; Accepted 5 January 2009; First published online 12 February 2009

Key words: Developing countries, psychiatrists, public health.

The great scarcity of psychiatrists in most countries of the world and the inequity in the global distribution of these specialists has been vividly illustrated by recent reports on mental health resources (WHO, 2005; Saxena et al. 2007). This scarcity is being further exacerbated by the migration of mental health specialists, both internationally from poorer to richer countries (Mullan, 2005) and within nations from poorer to richer regions and from public to private services. The contrast with the developed world is further exaggerated if we consider other mental health specialists such as clinical psychologists or psychiatric nurses. As a consequence, up to $90 \%$ of persons with mental disorders in low- and middle-income countries do not receive even basic mental health care (Kohn et al. 2004; Wang et al. 2007). In response to this crisis, the recent Lancet series on Global Mental Health called for action to close this astonishing treatment gap (Lancet Global Mental Health Group, 2007). The World Health Organization (WHO) launched the mental health Gap Action Programme (mhGAP) on 9 October 2008, its new flagship programme for scaling up services for the people with mental disorders in low- and middle-income countries. A new Movement for Global Mental Health (www.globalmentalhealth. org) was launched the following day to facilitate a global coalition of diverse mental health actors to strengthen the scientific and human rights evidence base to fuel a global advocacy campaign (Anon, 2008). This commentary considers what the role of

* Address for correspondence: Professor V. Patel, Sangath Centre, Porvorim, Goa, India 403521.

(Email: Vikram.patel@lshtm.ac.uk) psychiatrists should be in the context of these global mental health initiatives, and proposes a radical revision of the role of most psychiatrists.

In this review, I use the example of two countries whose mental health systems I know best: the UK and India. These countries represent the very extremes in mental health specialist resources and provide a stark comparison to make the case that psychiatry in lowand middle-income countries (comprising most of Asia, Africa and Latin America) must be practised in a fundamentally different way to well-resourced settings in western European, North American and Australian contexts. In short, the low-resource setting psychiatrist must be primarily a public health practitioner rather than a clinician.

The UK, with a population of about 60 million, is the home of nearly 5000 psychiatrists, a substantial proportion of whom originate from the Indian subcontinent (www.rcpsych.ac.uk/training/census.aspx). Although there are regional inequities in the distribution of mental health specialists in the UK, most parts of the country enjoy a respectable psychiatrist to population ratio. India, with a population of over 1 billion, is home to only about 3000 psychiatrists. These latter figures hide massive regional inequities within the country, with only a small proportion of psychiatrists practising in rural areas, which are home to two-thirds of India's population (Goel et al. 2004); furthermore, more than half the psychiatrists work purely in the private sector. These grotesque inequities are unlikely to be significantly affected by the output of psychiatrists for the foreseeable future and, incredibly, the picture in India is among the more promising ones of the developing world! 
What do these psychiatrists do? Although there are no systematic data on the nature of the day-to-day work by psychiatrists in India, there seem to be two main patterns of work. The first, which typifies most psychiatrists in both the private and public sectors, comprises face-to-face clinical encounters with individuals affected by mental disorder and their families. The second, which typifies most psychiatrists in medical schools or higher educational institutions, comprises a combination of individual clinical encounters; teaching of medical students, psychiatrists and other health professionals through a combination of lectures and guided clinical practice; and administration. A few, through sheer dint of hard work, squeeze in research and community-oriented activities. Thus, it would seem that the typical job profile of a psychiatrist, whether in public or private practice, is not too different from that in well-resourced countries. This is hardly surprising, as the psychiatric training in India mimics the heavily clinically oriented training UK trainees were given in the past.

A systematic review of epidemiological studies estimated prevalence of just five adult mental disorders in India to be about 7.5\% (Ganguli, 2000). Assuming that a fairly conservative estimate of $5 \%$ of the population is in need of biomedical mental health care, this would mean that there are about 55 million persons living in India who need mental health care each year. Based on the actual numbers of psychiatrists and the observations of what they spend most of their time doing, one can carry out a back of the envelope calculation of the numbers of these patients for whom the workforce of psychiatrists can provide a consultation. If every one of India's 3000 psychiatrists did nothing apart from individual clinical work, and assuming they worked 5 days a week throughout the year and saw an individual for a total of one hour during this period, they would, altogether, be able to see about 6 million persons in a year. This translates to about $10 \%$ of the overall burden of mental disorders in the country. Unsurprisingly, this figure approximates fairly well with recent estimates of the 'treatment gap' in low-income countries (Kohn et al. 2004; Wang et al. 2007).

What should the role of psychiatrists be in efforts to close the treatment gap? Put simply, if business as usual continues, psychiatrists will remain a largely irrelevant human resource and, as has been documented recently, even an obstacle (Saraceno et al. 2007) to the goal of closing the treatment gap. My position is that psychiatrists not only carry a moral obligation to be an integral partner in the scaling-up agenda but also have the scientific credibility and broad acceptance of policy makers and the community to be leaders in this process. Psychiatrists have been trained to excel in clinical care to reduce the suffering of mental disorder for an individual and his or her immediate social environment. We now need to emphasize strategies by which these unique skills can be extended to increase the coverage of care to as many people with mental disorders in our communities as we possibly can. In short, we need to move out of the clinics and into the populations that we serve and, in so doing, metamorphose from being clinicians to public health practitioners. This, indeed, is already the role that many pioneering psychiatrists in low-resource countries are championing. Their small numbers need to be heavily strengthened through the commitment of all psychiatrists, their professional bodies and those concerned with the education and employment of psychiatrists, to this larger role.

Being a public mental health practitioner must be grounded in the basic clinical skills with which psychiatrists are equipped. However, there are several others skills that need to be developed. Foremost of these is an understanding of the principles of public health that seek to improve the health of an entire population, with a strong commitment to equity, evidence, efficiency and accountability. In an environment of great scarcity of psychiatrists, not only are most people denied care but also the most vulnerable people such as the rural poor, are disproportionately deprived. To close the treatment gap, mental health care must be devolved to non-specialist health workers who are trained to deliver interventions for specific mental disorders. Task shifting, which refers to the strategy of rational redistribution of tasks among health workforce teams, has become a popular method to address specialist health human resource shortages. Specific tasks are moved, where appropriate, from highly qualified health workers to health workers with shorter training and fewer qualifications in order to make more efficient use of the available human resources for health. Our colleagues in other areas of medicine have been introducing and evaluating such interventions for decades. A Cochrane systematic review has reported that lay health workers show promising benefits in promoting immunization uptake and improving outcomes for acute respiratory infections and malaria, when compared to usual care (Lewin et al. 2005). The WHO has recently released global recommendations and guidelines on task shifting for scaling up HIV care and proposed the 'adoption or expansion of a task shifting approach as one method of strengthening and expanding the health workforce to rapidly increase access to HIV and other health services' (WHO, 2007).

The evidence base for task shifting in mental health care in developing countries, though comparatively young, is growing and is consistent in its findings. 
A series of controlled clinical trials evaluating such delivery mechanisms form the pivotal base for the new global mental health initiatives mentioned earlier. Thus, we now know that lay people or community health workers can be trained to deliver psychological and psychosocial interventions for people with depressive and anxiety disorders, schizophrenia and dementia (Bolton et al. 2003, 2007; Chatterjee et al. 2003; Ran et al. 2003; Dias et al. 2008; Rahman et al. 2008) in a diverse range of low- and middle-income countries. A crucial element of these task-shifting interventions, and a significant departure from earlier efforts to improve primary mental health care, is the role of mental health specialists extending well beyond the training phase to providing continuing supervision, quality assurance and support to the community health workers (Patel \& Kirkwood, 2008). In this respect, this model is no different from the 'collaborative' models of care that have been shown to be the most effective delivery systems for depression management in primary care in developed countries (Bower et al. 2006).

In the brave new world of global psychiatry, then, psychiatrists will need to be proficient in pedagogical skills for training and supervising non-specialist health workers; in the skills of monitoring and evaluation to ensure quality assurance of mental health care programmes; the core management skills essential for leading teams of health workers; and the critical skills of advocacy to champion the human rights of people with mental disorders - not only the right of access to evidence-based mental health care but also the very basic right to live without discrimination. In achieving these public health goals, the role of psychiatrists will need radical rethinking: put simply, aping the models used in comparatively very well-resourced settings, with their veritable armies of diverse mental health professionals (which, in fact, never seem enough to meet the needs of these countries), will not even dent the huge treatment gap in low- and middle-income countries.

\section{Acknowledgements}

V.P. is supported by a Wellcome Trust Senior Clinical Research Fellowship in Tropical Medicine.

\section{Declaration of Interest}

None.

\section{References}

Anon (2008). A movement for global mental health is launched [Editorial]. Lancet 372, 1274.
Bolton P, Bass J, Betancourt T, Speelman L, Onyango G, Clougherty KF, Neugebauer R, Murray L, Verdeli H (2007). Interventions for depression symptoms among adolescent survivors of war and displacement in northern Uganda: a randomized controlled trial. Journal of the American Medical Association 298, 519-527.

Bolton P, Bass J, Neugebauer R, Verdeli H, Clougherty K, Wickramaratne $P$, Speelman L, Ndogoni L, Weissman M (2003). Group interpersonal psychotherapy for depression in rural Uganda. Journal of the American Medical Association 289, 3117-3124.

Bower P, Gilbody S, Richards D, Fletcher J, Sutton A (2006). Collaborative care for depression in primary care. Making sense of a complex intervention: systematic review and meta-regression. British Journal of Psychiatry 189, 484-493.

Chatterjee S, Patel V, Chatterjee A, Weiss H (2003).

Evaluation of a community based rehabilitation model for chronic schizophrenia in a rural region of India. British Journal of Psychiatry 182, 57-62.

Dias A, Dewey ME, D'Souza J, Dhume R, Motghare DD, Shaji KS, Menon R, Prince M, Patel V (2008). The effectiveness of a home care program for supporting caregivers of persons with dementia in developing countries: a randomised controlled trial from Goa, India. Plos One 3, e2333.

Ganguli H (2000). Epidemiological findings on prevalence of mental disorders in India. Indian Journal of Psychiatry 42, 14-20.

Goel DS, Agarwal SP, Ichhpujani RL, Shrivastava S (2004). Mental Health 2003: The Indian Scene. In Mental Health: An Indian Perspective (1946-2003) (ed. S. P. Agarwal, D. S. Goel, R. Salhan, R. L. Ichhpujani and S. Shrivastava), pp. 3-24. Directorate General of Health Services, Ministry of Health and Family Welfare, Government of India/Elsevier: New Delhi.

Kohn R, Saxena S, Levav I, Saraceno B (2004). The treatment gap in mental health care. Bulletin of the World Health Organization 82, 858-866.

Lancet global Mental Health Group, Chisholm D, Flisher AJ, Lund C, Patel V, Saxena S, Thornicroft G, Tomlinson M (2007). Scaling up services for mental disorders: a call for action. Lancet 370, 1241-1252.

Lewin SA, Dick J, Pond P, Zwarenstein M, Aja G, van Wyk B, Bosch-Capblanch X, Patrick M (2005). Lay health workers in primary and community health care. Cochrane Database of Systematic Reviews 1, CD004015.

Mullan F (2005). The metrics of physician brain drain. New England Journal of Medicine 353, 1810-1818.

Patel V, Kirkwood B (2008). Perinatal depression treated by community health workers. Lancet 372, 868-869.

Rahman A, Malik A, Sikander S, Roberts C, Creed F (2008). Cognitive behaviour therapy-based intervention by community health workers for mothers with depression and their infants in rural Pakistan: a cluster-randomised controlled trial. Lancet 372, 902-909.

Ran MS, Xiang MZ, Chan CL, Leff J, Simpson P, Huang MS, Shan YH, Li SG (2003). Effectiveness of psychoeducational intervention for rural Chinese families experiencing schizophrenia: a randomised controlled trial. Social Psychiatry and Psychiatric Epidemiology 38, 69-75. 
Saraceno B, van Ommeren M, Batniji R, Cohen A, Gureje O, Mahoney J, Sridhar D, Underhill C (2007). Barriers to improvement of mental health services in low-income and middle-income countries. Lancet $\mathbf{3 7 0 ,}$ 1164-1174.

Saxena S, Thornicroft G, Knapp M, Whiteford H (2007). Resources for mental health: scarcity, inequity, and inefficiency. Lancet 370, 878-889.

Wang PS, Aguilar-Gaxiola S, Alonso J, Angermeyer MC, Borges G, Bromet EJ, Bruffaerts R, de Girolamo G, de Graaf R, Gureje O, Haro JM, Karam EG, Kessler RC, Kovess V, Lane MC, Lee S, Levinson D, Ono Y,

Petukhova M, Posada-Villa J, Seedat S, Wells JE (2007).

Use of mental health services for anxiety, mood, and substance disorders in 17 countries in the WHO world mental health surveys. Lancet 370, 841-850.

WHO (2005). Mental Health Atlas 2005. World Health Organization: Geneva.

WHO (2007). Task Shifting: Global Recommendations and Guidelines. World Health Organization: Geneva. 